\title{
SONGS OF INNOCENCE AND EXPERIENCE: DOMINANCE FEMINISM IN THE UNIVERSITY
}

\section{Kathryn Abrams}

Editor's note: This article is based on a book review of The Morning After: Sex, Fear, and Feminism on Campus, by Katie Roiphe. Reprinted by permission of the Yale Law Joumal Company and Fred B. Rotham and Company from the Yale Law Journal, vol. 103, pp. 1533-60.

Feminists have had notorious difficulty handling challenges from within our ranks. The "sex wars" struggle, in which opponents of pornography and advocates of sexual expression tarred each other with claims of false consciousness, produced lingering hostilities. Mainstream feminists first decried the race critique as freighting their efforts with "extra baggage" and only slowly recognized that it exposed a dynamic of erasure within feminism itself. In the wake of the antagonism and wasted effort produced by those failures, some feminists have voiced an unsteady resolve: to give ear to the unorthodox in feminism, to attempt to reconceive feminist efforts along pluralist lines.

That resolve has been challenged by the emerging controversy over "date rape" on university campuses. Camille Paglia fired the first shot, charging that campus rape policies resurrect parental protection, creating a generation of women unable to enjoy the "sizzle" of sex or protect themselves against its inevitable excesses. Paglia's scattershot cultural indictment and adulation of a dark, immutable male sexuality ("guess what, it's hot") confounded her message and made it difficult to gauge her target. Yet Paglia's challenge has been seconded in ways that are more difficult to ignore. Writing in the New York Times Magazine, Katie Roiphe warned that exaggerated claims of date rape "betray feminism" by portraying women as fragile, vulnerable, and unable to negotiate the "libidinous jostle" of contemporary life without paternalistic rules and restrictions. With the publication of her book The Morning After: Sex, Fear, and Feminism on Campus, Roiphe adds to the date rape critique the voice of an author explicitly concerned about the future of feminism.
Roiphe's book is ultimately unsatisfying, for both stylistic and substantive reasons. Its narrative is bathed in secondhand nostalgia for a golden age of sexual revelry that Roiphe never witnessed. Its subtext - that sexualized oppression is mainly a problem inside women's heads-is absurd outside the rarefied atmosphere Roiphe describes and makes little sense within it. Its relentless portraits of shrill campus leaders and their sulking, maladjusted followers will try the patience of all but the most generous feminist readers. Yet the book's larger message is one that feminists cannot afford to ignore. As a student drawing on recent experience, Roiphe speaks from the vortex of the controversy. While her rhetoric reflects the current taste for mocking "political correctness," her concern with women's fear-filled abdication of the sexual tealm has a more established pedigree.

Roiphe's book voices the concerns of a subset of feminists, women old enough to have participated in the "sex wars" and young enough to dominate "Generation X." These women worry about whether depictions of pervasive male aggression and coercion imply female passivity and whether advocacy of expanded legal protection signals a return to paternalism or undermines a woman's assertion of individual responsibility for her own direction and security. They want to fight against the oppression of women without surrendering their belief in the present possibility of women's agency. The publication of Roiphe's book provides an occasion for feminists who do not share her views to think seriously about how to respond.

\section{"OOWN BY LAW"?}

Feminists might begin by disaggregating the parts of the negative imagery Roiphe invokes. One reason that women within the dominance framework are viewed by critics as passive or dependent is that they rely on mechanisms provided by the state, the university, or other institutions to challenge sexualized injury.
Roiphe's

book voices the

concerns of $a$

subset of

feminists, women

old enough to

have participated

in the "sex wars"

and young enough

to dominate

"Generation X." 
We might ask, first, why the resort to state or other quasi-legal protections should connote dependence, vulnerability, or passivity. In fact, recent memory offers potent counterexamples of groups whose resort to law was not associated with images of vulnerability or dependence. Black litigants in 1960 s school desegregation suits were not viewed by observers as "cowering" behind a wall of legal rights. They were depicted as asserting themselves, claiming their rights, and pressing strongly for the rectification of injustices. Why are 1960s blacks (a group that included women) and 1990s women (a group that includes blacks) depicted in such different ways? One explanation may be that civil rights activists were prepared to rally, march, engage in nonviolent resistance, and expose themselves to considerable physical danger, in addition to litigating their cause. Yet feminist activists also rely on methods other than litigation; critiques of feminist rallies and educational initiatives occupy much of Roiphe's book. Other factors seem to be at work in shaping contrasting images of the two overlapping groups.

One factor may be the mediating stereotypes through which the actions of each group are inter- preted. Most people interpret the actions of those around them in light of stereotypes, which include not only stigmatizing caricatures but also shorthand explanations that help people assimilate complex aggregations of facts. One factor that encourages the disparate imagery remarked above is that the actions of the groups "blacks" and "women" tend to be interpreted according to different stereotypes. Women invoking legal protections may be characterized as dependent or vulnerable, because women, as a group, have often been characterized as vulnerable and dependent. Moreover such characteristics have explicitly been invoked, sometimes by women, in seeking state intervention on their behalf.

An additional piece of the puzzle--that explains why black litigants have not been characterized in that way, although some of them are women, and female litigants have, although some of them are black-is provided by the analysis of Kimberle Crenshaw. Crenshaw argues that cultural imagery relating to blacks reflects popular perceptions of black men, whereas cultural imagery relating to women reflects popular perceptions of white women, thereby dichotomizing the relevant imagery in ways

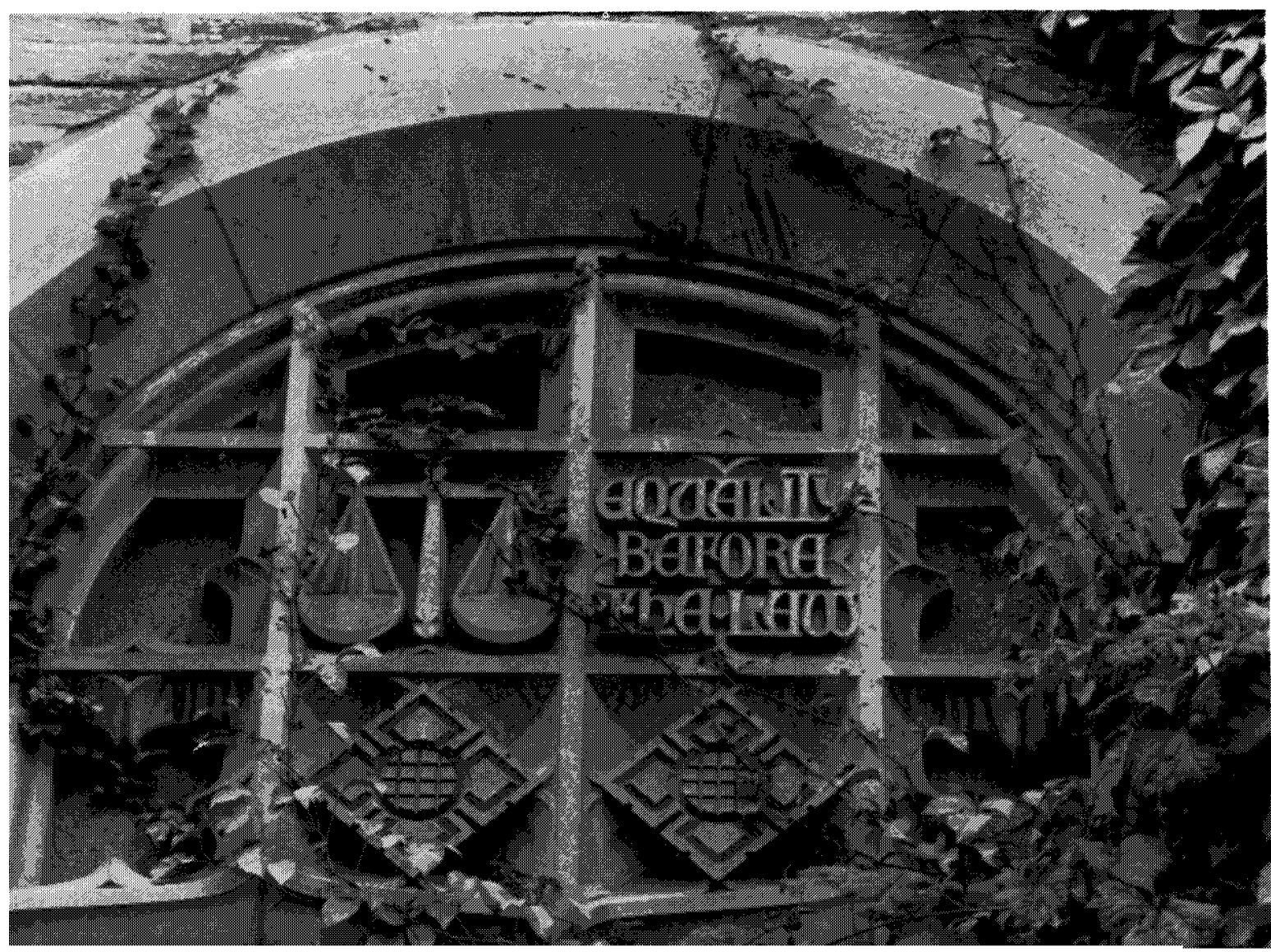

viewed by

observers as

"cowering"

behind a wall of

legal rights. 
that would not be possible were the images to address the experiences of black women.

Changing social views of government intervention may be a second factor shaping the divergent perceptions of the resort to law. Black civil rights litigants may have escaped characterization as vulnerable or dependent because the government protection invoked by litigation was not, at that time, understood to imply dependence. A Reaganera mobilization of public sentiment against Great Society programs has resulted in a reconceptualization of governmental protection; it is now more likely to be construed as conferring an unearned advantage or as connoting the dependent character of the beneficiary. As the increasingly acrimonious debates over affirmative action and welfare reform have demonstrated, these images now impede African American men and women, as well as women of a variety of races.

A third reason for the divergence in the images may be the unexamined assumption of a publicprivate distinction. Exclusion from a school system is, according to this framework, a public wrong, which makes (public) legal redress entirely appropriate. However, sexualized injuries-particularly those such as date rape and sexual harassment that occur between acquaintances-are thought to be private wrongs. Despite the fact that they have been rendered public by the creation of a legal claim, some critics persist in seeing their prevention or rectification as a private matter, a matter of individual responsibility. Thus the resort to legal means in such cases represents the failure of individual responsibility - the woman's responsibility-to prevent or resolve the problem.

Feminist theory attempts to explain why reliance on that distinction is inappropriate. It is shortsighted to call a sexualized injury private when the creation of a legal claim acknowledges its social consequences. Interactions in the "private" realm are so critically shaped by influences that have their origins in the "public"-from economic inequalities to institutional sanctions that reinforce gender role expectations - as to make a rigid boundary between the two incoherent. That analysis explains why private responses may be unavailing and why the resont to law itself represents no failure. Yet it also highlights a different aspect of the negative imagery in question: a female victim so multiply compromised that she is unable to avert or address such injuries herself. It is an image that is inconsistent with some women's experience of, or aspiration for, autonomy.

\section{WOMEN'S VICTIMIZATION AND MOMEN'S AUTONOMY}

But why is a given woman's experience of, or aspiration for, autonomy inconsistent with the recognition of socially created obstacles that prevent many women from addressing sexualized injury on an individual basis? When feminist theorists say that we should permit women recourse to law without requiring them toaddress offenders on their own, they are not necessarily saying that women are intrinsically unable to resist acquaintance rape or speak straightforwardly to sexual harassers. It is important, in light of critiques such as Roiphe's, to ask how those positions have become confused, to the detriment of feminist efforts at reform.

How the revelation of constraints on a group comes to be understood as a statement implicating any given individual is the first question that requires attention. The confusion reflects, in part, a misapprehension by feminism's critics. The decision to authorize legal intervention in response to particular acts may imply no statement whatsoever about the acts' victims. Laws that make theft or assault a crime make no statement about the capacity of victims and require nothing more than that victims give evidence. Even laws that premise intervention in part on the difficulties faced by victims in effecting private resolution do not claim to describe all members of the victim class. They may be based on the probability of barriers to individualized response or the probability of barriers in the most serious cases. But they are not inconsistent with the possibility of an assertive response by an individual victim, nor does the existence of such a response cast doubt on a legislative scheme.

However, the connection between group-based statements and individual inferences is not based wholly on a misunderstanding. The emerging link between dominance theory and the rhetoric of recovery may also contribute to the confusion. A recovery approach supplements the social-victim message of feminist theory with an emphasis on individual victimization. Its focus on individualized response to injury, as Roiphe notes, can make the experience of the victim central to participants' selfconceptions. Its suggestion that the world is full of "walking wounded" who have not yet discovered

\section{Govern-}

mental protection

is now more likely

to be construed as

conferring an

unearned

advantage or as

comnoting the

dependent

character of the

beneficiary. 
their injuries creates a personal parallel to dominance feminism's political claim that practices such as rape and spousal abuse are more pervasive than most people suspect.

Yet, contrary to Roiphe's suggestion, that conjunction is neither the intentional product of dominance theorists nor the inevitable result of their arguments. One can read reams of dominance theory without encountering the thetoric of recovery; even in Roiphe's critical exposition, MacKinnon prods students toward concerted political action rather than self-absorption. If that merger has become a problem, it is more indicative of a reversible mistake in feminist strategy than a substantive flaw in the theory of women's sexual victimization.

How the notion of constraints on women's ability to respond comes to be understood as an "insult" is a more important question. Here a crucial factor is the widespread assimilation of liberal precepts. According to liberal theory, the qualities that are most distinctive and valuable in human beings are those that inhere by virtue of their universal human nature. Prime among them is autonomy, the ability to direct one's life through the exercise of unencumbered choice. For those who have been socialized to an incompletely reflective acceptance of such precepts, there is something doubly insulting about being identified by apparently contingent, nonuniversal, group-based qualities and being described as unable to transcend the psychological or economic constraints that those qualities impose on autonomous self-direction. To be a woman constrained by the incidents of a sexist society, in this view, is to suffer a kind of compromised personhood. Addressing that argument has proved a difficult task, as dominance feminists have been obliged to respond both to its underlying premises and to the complicating contexts in which they have been applied.

That response has enjoyed the greatest success in the realm of political theory, where liberal precepts are subject to the clearest articulation and response. Dominance feminists and others have challenged the notion of autonomy as the incident and measure of personhood from a range of different starting points. Theorists more sympathetic to liberal premises have sought to integrate descriptions of partially compromised autonomy into liberal theory, depicting unencumbered choice as a human potential that is only incompletely and differentially realized under present circumstances. Other theorists have rejected the notion of a universal, presocial human nature in favor of a view emphasizing social construction. In their view, the most salient characteristics of people are forged in the limitless domain of the social, by singular or multiple structures of oppression. Group-based characteristics and constraints are neither exceptional nor demeaning; they are, rather, predictable incidents of social construction. Such theorists, in general, seek to displace liberal precepts but may also endeavor to accommodate them. Seeking partly to explain the possibility of resistance under assumptions of social construction, some theorists have described in that context a limited human agency-the capacity to maneuver within institutional or cultural constraints.

Those efforts at revision, modestly successful at the level of theory, have encountered greater barriers in the areas of law and popular discourse. Lay critics of a dominance-based vision do not always understand the extent to which dichotomous assumptions about autonomy and incapacity affect their thinking or the fact that alternative assumptions are possible. Those who understand their assumptions in a more self-conscious way may cling to the notion of unencumbered choice, if not as a present description, then as a statement of aspiration or an expression of potential. They may find notions of partially compromised autonomy discouraging or see notions of a complex, divided self as inaccessible and off-putting.

In the legal context there are other problems. Feminist legal advocates do not simply, or even primarily, advance arguments about autonomy, social construction, or the decentered self. They seek instead to win discrete legal battles. The latter goal may initially be furthered by accepting rather than challenging the liberal assumptions of legal decision makers.

Feminists working in the area of spousal abuse, for example, chose to counter decision makers' assumption that battered women exercise unencumbered choice by interposing images of unusual passivity or incapacity (i.e., "learned helplessness"). That strong account of compromised capacity did not challenge judges' assumption of autonomous choice but highlighted the possibility of exceptions created by extreme circumstances. While the strategy was initially successful, it set in motion a series of damaging dynamics. Battered women recoiled in confusion and denial from the images of exceptional
Feminist

legal advocates do not simply, or even primarily, advance arguments about autonomy, social construction, or the decentered self. They seek instead to win discrete legal battles. 
passivity; judges who used such images in an exculpatory fashion in the context of battered women's self-defense began to use them punitively in related custody proceedings. When battered women's advocates offered more complex, less fully compromised images of their clients, judges heard unqualified images of incapacity. Their commitment to a dichotomous world of autonomous individuals and pathological exception, reinforced in some cases by the early arguments of battered women's advocates, made it hard to understand that advocates were interposing an unfamiliar image of human possibility.

A related dynamic may play a role in the acquaintance rape debate. To counter the widespread belief that women exercise free choice in the context of sex with acquaintances, dominance feminists have stressed a pattern of cultural and institutional practices, culminating in the actual sexual encounter, through which women's autonomy has been largely negated by male sexual coercion. Women's constraint, in this account, is no longer a narrow exception; it is, rather, part of a dichotomous depiction in which autonomy remains the norm, but women, as a class, are prevented from achieving it. The topsy-turvy social world of The Morming After attests, in exaggerated form, to the responses that may be generated by that depiction. Although some women feel vindicated by the revelations of male domination, others have begun to recoil from the wholly compromised image of women they believe it suggests. In addition, many participants, habituated by their own dichotomous premises and by the strong account of the domination of women, have become unable to discern the more qualified accounts of both male and female agency that have sometimes been offered by feminist advocates.

Feminists must consider how to integrate the more complex accounts of human nature and agency that have informed recent theoretical discussions into popular and legal debates. Although that task is only now at its inception, it is possible to sketch its general outlines. It will require, first, mobilizing the appropriate imagery in describing the lives of women. Contradiction and complexity, shifting combinations of choice and restriction, will need to be depicted in concrete terms that a range of audiences can understand. The task will also require an interpretive framework that emphasizes that such complex, constrained images are not exceptional or pathological; though the particular constraints may

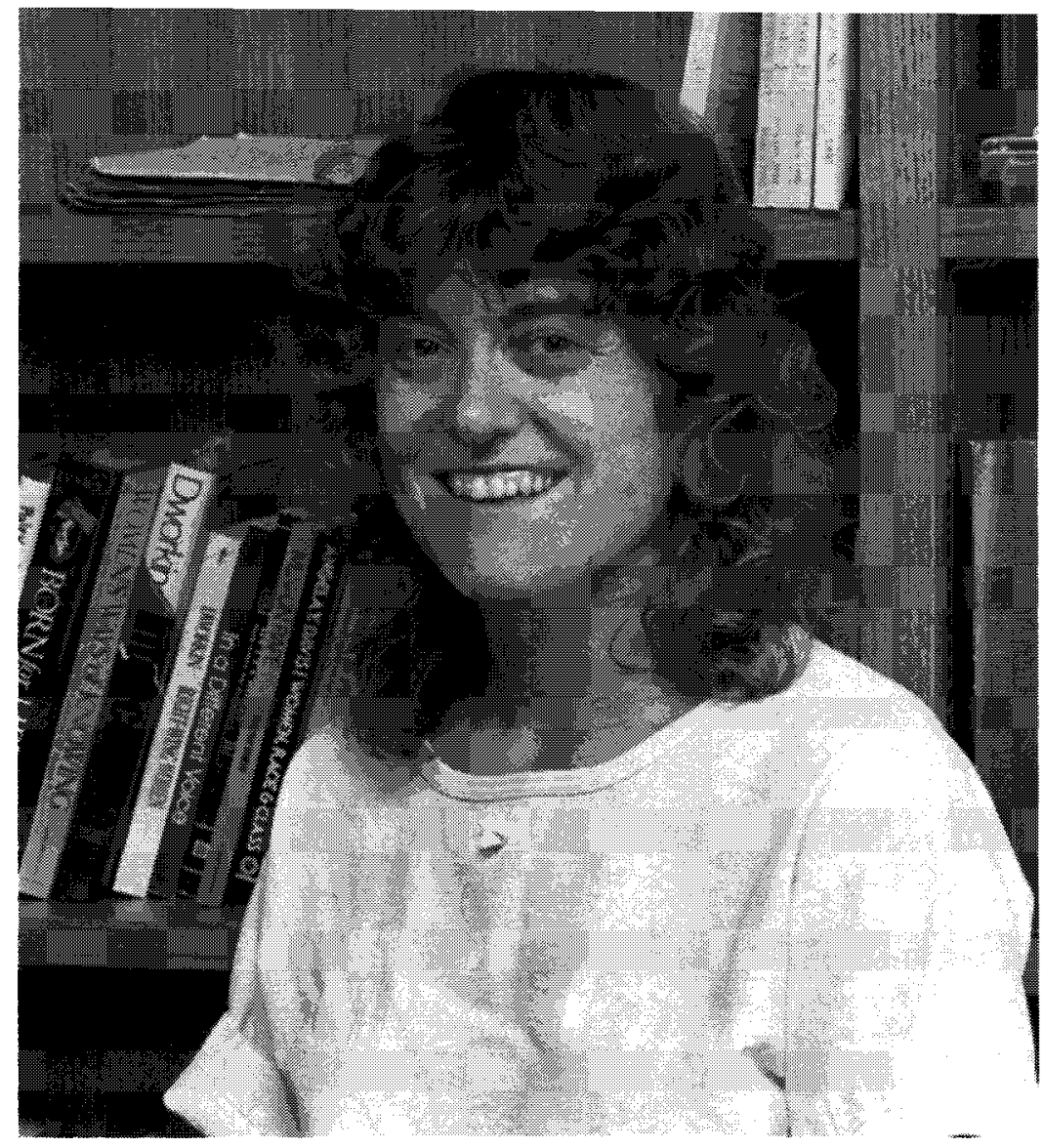

be specific to the circumstances of a group, the distance from a condition of unencumbered autonomy is more widely shared. Finally, feminists will need to address the features of the legal world that make accounts of partially compromised autonomy or complex, divided identities difficult to accommodate or comprehend. As the larger task of conceptual transformation proceeds, however, feminists must also respond to the need for a more practical education, particularly in the university setting.

\section{CONCLUSION}

It would be wrong to view Roiphe as the primary instigator of the kinds of inquiries outlined above. At best, her narrative reiterates, in less nuanced form, critiques that were offered a decade ago by Ellen Willis, Joan Nestle, and others; at worst, it reduces the vexed rerritory of contemporary women's lives to a problem of their own making. Yet seizing the attention of a politically complacent public, as we learned in the aftermath of Anita Hill's testimony, is a large part of the battle. If Roiphe's book is vivid and tendentious enough to bring those issues before a wider public, even so flawed a work can make an important contribution.
Kathryn Abrams is a professor of law at the Cornell Law School and an associate professor in Cornell University's Program on Ethics and Public Life. 


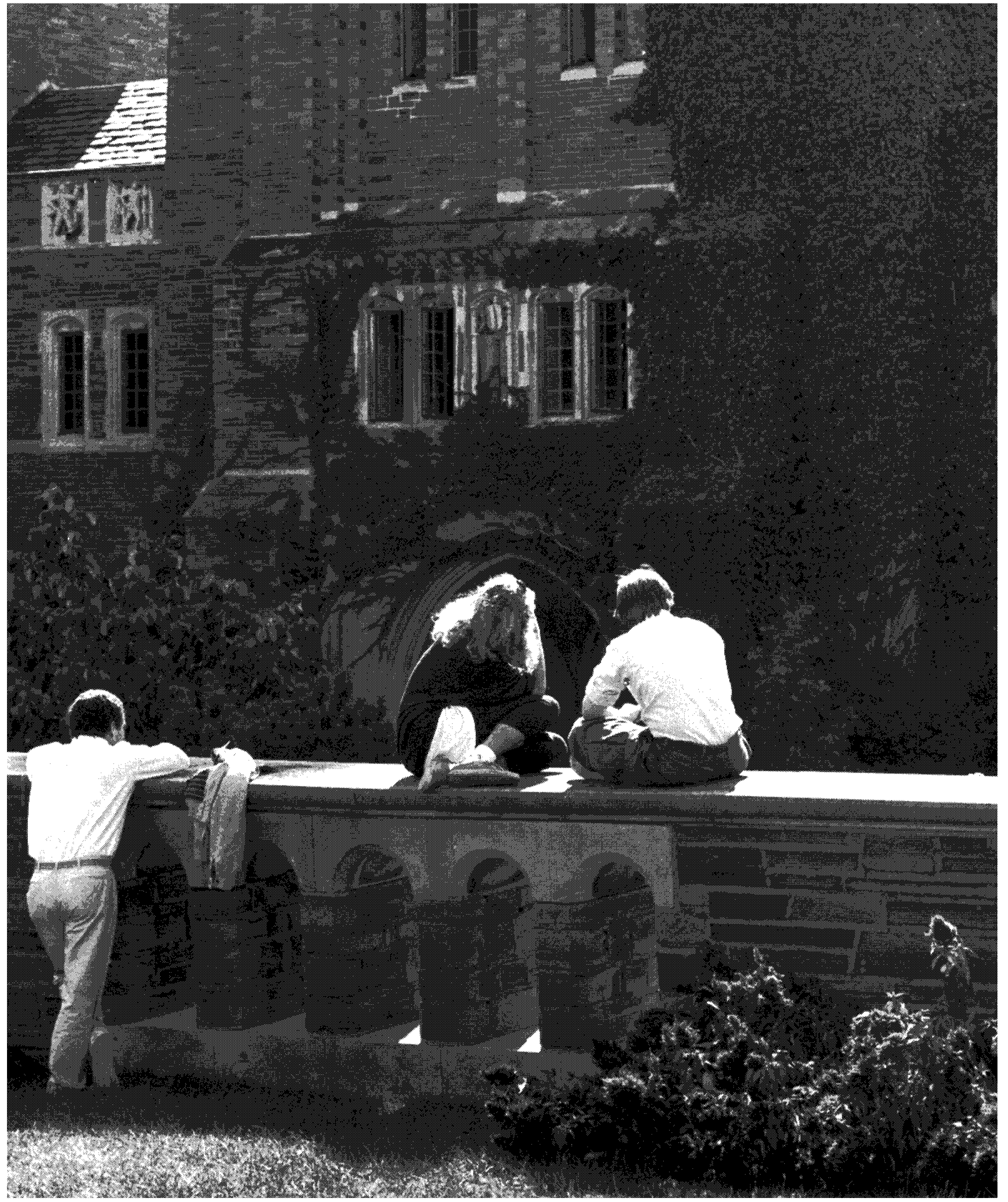

